\title{
Update on the use of memantine in Alzheimer's disease
}

\section{Robert J van Marum}

Geriatric Department, University Medical Center Utrecht, Utrecht, The Netherlands
Correspondence: Robert (Rob) J van Marum, Geriatric Department, B05256, University Medical Center Utrecht, PO Box 855000, 3500 GA, Utrecht, The Netherlands

$\mathrm{Tel}+3$ I 887558280

Fax +3। 302544397

Email r.j.vanmarum@umcutrecht.nl

\begin{abstract}
Memantine is a low to moderate affinity N-methyl-D-aspartate receptor (NMDAR) antagonist. The effects of memantine in Alzheimer's disease (AD) have been studied in 7 randomized controlled trials in many post-hoc analyses. Three out of four RCTs in patients with moderate to severe AD (Mini Mental State Examination [MMSE] < 14) showed a statistically significant but clinically small positive effect of memantine on cognition, global functioning, activities of daily living (ADL) and neuropsychiatric symptoms. No effects on these outcome measures could be found in the three RCTs studying patients with mild to moderate AD (MMSE 14-24). Two of these studies evaluated the effect of addition of memantine to donepezil. Only the study in patients with mild to moderate AD showed a positive effect of addition of memantine on cognition, ADL, global functioning and neuropsychiatric functioning. Cost-effectiveness of memantine therapy remains controversial. Post-hoc analyses and observational studies suggest some effects on agitation/aggression, delusions or hallucinations. Side effects of memantine are usually mild and seem to be comparable with placebo. In this review, an oversight of pharmacodynamics and pharmacokinetics of memantine is presented. Also, published data concerning efficacy and safety in patients with AD are presented.
\end{abstract}

Keywords: dementia, Alzheimer's disease, drug therapy, memantine

\section{Introduction}

Memantine is a low to moderate affinity N-methyl-D-aspartate receptor (NMDAR) antagonist that was approved as a therapeutic drug in moderate to severe Alzheimer's disease (AD) in 2002 by the European Agency for the Evaluation of Medicinal Products (EMEA), followed in 2003 by the USA Food and Drug Administration (FDA). Despite this relatively recent approval for $\mathrm{AD}$, memantine is not a new drug. Eli Lilly synthesized it in the early sixties as a drug for the treatment of diabetes mellitus. ${ }^{1}$ In the 1980s, it was studied as a drug for various neurological diseases (eg, Parkinson's disease, neurogenic bladder disorders, coma). In 1986, the first report of the use of memantine (intravenous) in patients with AD was published. ${ }^{2}$ In this small $(n=20)$ and probably underpowered study, no positive effects of memantine could be found on several measures of global and neuropsychiatric functioning. More than 10 years later, the results of a larger double-blinded, randomized controlled trial (DBRCT) led to contacts with EMEA for approval of memantine as a drug for the treatment of moderate to severe $\mathrm{AD} .{ }^{3}$ Before approval, the EMEA requested a second randomized controlled trial which was conducted in $2000 .{ }^{4}$ Based on these two studies, memantine was approved as an AD drug in Europe. Despite this registration, discussion concerning the clinical effectiveness of memantine is going on. In their 2007 report of final appraisal determination, the UK National Institute for Health and Clinical Excellence (NICE) states "Memantine is not recommended as a treatment option for patients with moderately severe to severe Alzheimer's disease except as part of well designed clinical studies." This is however in contrast with the decision in many other countries, based on the same information, to reimburse the use of memantine. In this 
review, an oversight of pharmacodynamics and - kinetics of memantine is presented. Also data concerning efficacy and safety in patients with $\mathrm{AD}$ are presented.

\section{Pharmacodynamics}

In the central nervous system (CNS), two types of receptors can be found: the ionotropic (excitatory) and metabotropic (excitatory or inhibitory) receptors. Ionotropic receptors are formed by multiple proteins that are coupled to an ionic channel. Following activation of this receptor, the ion channel will open, permitting cations or anions to enter or leave the cell. Metabotropic receptors are smaller and consist of only one protein that is coupled to a transducer protein. This transducer protein interacts with a primary effector inside the cell, which then interacts with a "second messenger". ${ }^{6}$ Memantine is a glutamate antagonist, blocking the ionotropic NMDAR. ${ }^{7}$ Glutamate is one of the major excitatory neurotransmitters in the brain and spinal cord and is considered of importance in learning processes. High concentrations of glutamate, leading to excessive NMDAR activity with increased inflow of $\mathrm{Ca}^{2+}$ through the ion channel are thought to result in excitotoxicity, a pathological process where neuronal injury or death occurs. Besides the NMDAR, three other glutamate receptors can be found: the ionotropic $\alpha$-amino- 3 hydroxy-5-methylisoxazole-4-propionacid (AMPA) and kainacid receptors and a metabotropic glutamate receptor. The NMDAR consists of four subunits. The genes encoding these subunits, NR1 (GRIN1), NR2 (GRIN2A, GRIN2B, GRIN2C, and GRIN2D), and NR3 (GRIN3A and GRIN3B) were identified just less than two decades ago. A functional NMDA receptor typically contains two NR1 and two NR2 subunits. Occasionally, a NR3 subunit is included. Glutamate can bind as an agonist to the NR2 subunits. For activation of the receptor, binding of co-agonist glycine (or occasionally D-serine) to the NR1 subunits is also required. However, binding of these agonists is not sufficient for functional opening of the ion channel. Opening is also voltage-dependent. Within the channel pore, a binding site for magnesium $\left(\mathrm{Mg}^{2+}\right)$ is located. At resting membrane potential, $\mathrm{Mg}^{2+}$ binds to this site, blocking ion flow (especially $\mathrm{Ca}^{2+}$ ) through the channel. Since glutamate will also interact with postsynaptic AMPA receptors, $\mathrm{Na}^{+}$ influx through this channel will change membrane potential. When the membrane becomes depolarized, $\mathrm{Mg}^{2+}$ is expelled from the channel allowing passage of ions. Thus, both depolarization of the postsynaptic neuron and binding of agonists at NR1 and NR2 is required for flow of $\mathrm{Ca}^{2+}$ through the NMDAR channel. In $\mathrm{AD}$, glutaminergic neurons show overactivation, releasing more and continuously glutamate compared to non-AD state. ${ }^{7}$ Also, the NMDAR is more sensitive for glutaminergic stimulation. In these situations of overexcitation, $\mathrm{Mg}^{2+}$ is not capable of blocking the channel sufficiently, leading to excess inflow of $\mathrm{Ca}^{2+}$. This excess $\mathrm{Ca}^{2+}$ influx into cells activates a number of enzymes damaging cell structures (eg, cytoskeleton, membrane and DNA). Memantine blocks the open ion channel in a $\mathrm{Mg}^{2+}$ manner. After blockade of the channel, agonists will unbind from the receptors and the ion channel will close, trapping memantine inside. Memantine is called an "uncompetitive" blocker because it does not compete with agonists at binding sites. Other than $\mathrm{Mg}^{2+}$, memantine is less pronounced voltage dependent and therewith more capable of blocking the channel in case of overstimulation by excess glutamate. It will dissociate from the NMDAR channel upon depolarization in case of normal physiological activation, but will remain blocking the channel during moderate long-lasting depolarization, as during chronic excitotoxic conditions. The concept of NMDA overstimulation leading to excitotoxicity is not AD specific. Also in many other neurological diseases (eg, multiple sclerosis, Parkinson's disease, Huntington's disease, epilepsy, acute stroke, neuropathic pain), NMDA overactivation may contribute to pathophysiology. ${ }^{8}$ Besides having a role in direct neuronal death, hyperactive NMDARs have also been associated with neurofibrillary degeneration and tau toxicity in Alzheimer's disease. ${ }^{9,10}$

Memantine was found to inhibit NMDARs with an IC50 of approximately $1 \mathrm{mM}$, which is reached at the normal dosing range. At high concentrations $(10-500 \mathrm{mM})$, memantine affects many CNS targets, including serotonin and dopamine uptake, nicotinic acetylcholine receptors (nAChRs), serotonin receptors, sigma- 1 receptors, and voltage-activated $\mathrm{Na}^{+}$channels. ${ }^{7}$

\section{Pharmacokinetics}

The recommended starting dose of memantine is $5 \mathrm{mg}$ once daily, with a target dose of $20 \mathrm{mg} /$ day. The dose should be increased in $5 \mathrm{mg}$ increments to $20 \mathrm{mg} /$ day ( $10 \mathrm{mg}$ twice daily), with a minimum of one week between each dose titration. ${ }^{11}$ Recently, a once-daily formulation has become available. Following oral ingestion, memantine is almost completely absorbed. Food has no effect on its absorption. Since it is not subject to major metabolism in the liver, plasma levels are similar to the given dose. Peak plasma levels are reached within 5-6 hours (t-max). Peak plasma concentration (Cmax) following a single $20 \mathrm{mg}$ oral dose of memantine ranges between 22 and $46 \mathrm{ng} / \mathrm{mL}$. Steady state levels are reached around day 11 with accumulation in plasma resulting in approximately 3 to 4 times Cmax compared with that following a single 
dose. Memantine is protein bound for approximately $45 \%$. It has a distribution volume of $9 \mathrm{~L} / \mathrm{kg}$, indication major tissue distribution. The terminal half-life is 60 to 100 hours. Since aging is associated with polypharmacy, potential drug-drug interactions may be important in drug selection. The risk of interactions of memantine with other drugs is low. It is not a substrate for phase I metabolization (cytochrome P-450). No influence of known inducers or inhibitors of individual sub-families of CYP450 (CYP 2A6, CYP2C9, CYP 2D6, CYP 2E1, CYP 3A, CYP 1A2) has been found in interaction studies. Especially important, no interactions with cholinesterase inhibitors have been found. ${ }^{12-14}$ A small proportion of memantine is metabolized through a phase II reaction in which multiple polar metabolites are formed as a result of conjugation or hydroxylation (memantine N-gludantan conjugate, 4-and 6-hydroxy memantine and 1-nitroso-deaminated memantine). However, none of these metabolites show clinically relevant effects. Since moderate hepatic impairment (Child-Pugh A and Child-Pugh B) does not alter the pharmacokinetics of memantine, no dosage adjustment is needed in these stages. No data on the use of memantine in patients with severe hepatic impairment are available. Memantine clearance is mainly dependent on renal function. Renal excretion accounts for $65 \%$ to $90 \%$ of the clearance of unchanged memantine. The remaining part can be found in bile and feces. The formed metabolites are mainly excreted by the kidney. Renal clearance involves active tubular secretion moderated by $\mathrm{pH}$-dependent tubular reabsorption. In patients with a renal clearance between 30 and $50 \mathrm{~mL} / \mathrm{min} / 1.73 \mathrm{~m}^{2}$, exposure is about $60 \%$ increased. No dose reduction is advised in this range. Dose titration in these patients should be performed cautiously and based on side effects. In patients with a renal clearance between 10 and $30 \mathrm{~mL} / \mathrm{min} / 1.73 \mathrm{~m}^{2}$, exposure is doubled compared to controls. ${ }^{15}$ The maximum daily dose in these patients should be set at $5 \mathrm{mg}$ twice-daily. Since renal function may decline as result of newly prescribed medication (eg, non-steroid anti-inflammatory drugs, diuretics, ACE inhibition), side effects of memantine may develop in patients who have used memantine for some period. The pharmacokinetics of memantine can be significantly affected by high or low urine $\mathrm{pH}$ values. ${ }^{16}$ Alkaline urine $\mathrm{pH}$ results in reduced renal excretion and renal clearance, while acidic urine $\mathrm{pH}$ may result in increased renal clearance of memantine.

\section{Efficacy of memantine in AD}

\section{Endpoints in $A D$ trials with memantine}

The effects of memantine in AD have been studied in both patients with mild to moderate AD (Mini Mental State
Examination [MMSE]: 14-24) and patients with moderate to severe AD (MMSE < 14). Primary endpoints in AD trials required by most regulatory authorities for granting a drug license are 'global functioning' and 'activities of daily living' (ADL). In patients with mild to moderate $A D$, cognition is also considered a compulsory primary endpoint. ${ }^{17}$ The effects of drugs on behavioral symptoms are considered secondary outcomes.

\section{Assessment of global functioning ${ }^{18}$}

Until now, this is preferably measured with the Clinician's Interview-Based Impression of Change Plus Caregiver Input (CIBIC-Plus) or the Clinical Dementia Rating (CDR). The CIBIC-Plus measures overall levels of cognition, function, and behavior through the use of patient interviews along with caregiver observations. It is scored as a 7-point categorical rating, ranging from a score of 1 (indicating "markedly improved") to a score of 7 (indicating "marked worsening"). The CDR is a 5-point scale used to characterize six domains of cognitive and functional performance applicable to Alzheimer disease and related dementias. The necessary information to make each rating is obtained through a semi-structured interview of the patient and a reliable informant. The Global Deterioration Scale (GDS) separates the course of dementia into 7 stages. The Functional Assessment Staging Tool (FAST) separates deterioration into 16 stages.

\section{Assessment of ADL}

In most studies, ADL is assessed with the Alzheimer's Disease Cooperative Study (ADCS) ADL scale. The ADCS-ADL is administered as an interview with the caregiver and is focused on the performance of each ADL during the prior 4 weeks. ${ }^{6}$ Possible scores range from 0 to 54 , a higher score indicating better ADL function. ${ }^{21}$ In severe AD, the Behavioral Rating Scale for Geriatric Patients (BGP)-Care Dependency subscale can also be used. ${ }^{22}$ The BGP consists of 35 items (scored 0,1 , or 2 by the rater) assessing observable aspects of cognition, function and behavior. ${ }^{16} \mathrm{~A}$ higher score reflects worse function. The BGP care dependency subscale reflects cognitive and functional characteristics associated with increased need for care.

\section{Assessment of cognition}

In moderate to severe $\mathrm{AD}$, cognition is often assessed with the Severe Impairment Battery (SIB), which, compared to the easier to use MMSE, is more appropriate for the assessment of cognition in severe AD patients (MMSE 
below 12 points). The SIB is a 100-point, 40 item test. Higher scores indicate better functioning. The AD Cooperative Study group reported that for untreated patients with $\mathrm{AD}$ with MMSE scores of 5 to 9 , the mean deterioration rate on the SIB was roughly 3.19 per month and for untreated patients with AD with MMSE scores of 10 to 15 , the rate of change was 2.08 per month. ${ }^{19}$

In mild to moderate $\mathrm{AD}$, cognition is mostly assessed with the Alzheimer's Disease Assessment Scale-Cognitive subscale (ADAS-Cog). ${ }^{20}$ The ADAS-Cog measures several cognitive domains, including memory, language and praxis. Total scores range from 0 to 70 , with higher scores indicating greater cognitive impairment. In general, regulatory authorities recognize a four-point change on the ADAS-Cog at 6 months as indicating a clinically important difference.

\section{Assessment of behavior}

The Neuropsychiatric Inventory (NPI) assesses behaviors common in dementia including delusions, hallucinations, agitation/aggression, dysphoria/depression, anxiety, euphoria, disinhibition, irritability, aberrant motor behavior, alterations in appetite, apathy, and changes in nighttime behavior. ${ }^{23}$ The scores are based on interviews with caregivers and assess behaviors that were present in the last 4 weeks. Frequency and severity scores are elicited from the caregiver with anchored ratings, and the total score for each domain is the product of the severity score (1-3) multiplied by the frequency score (1-4). The total score for the NPI is the sum of the individual domain scores, ranging from 0 to 144. The NPI also includes a caregiver distress rating. Caregivers rate their own distress associated with each behavior on an anchored scale of 0 to 5 . The total NPI distress score is the sum of the distress scores associated with each behavioral domain and can range from 0 to 60 . For both scales, higher scores reflect worse symptoms or distress

\section{Double blinded, randomized controlled trials in moderate to severe AD (Table I)}

Four double-blinded randomized controlled trials (DBRCT) comparing the effects of memantine with placebo in patients with moderate to severe AD have been published. 3,4,24,25

The first trial was the study by Winblad et al who studied the effect of memantine $10 \mathrm{mg} / \mathrm{d}$ during a follow-up of 3 months. ${ }^{3}$ The patient population studied in this study contained both patients with $\mathrm{AD}(\mathrm{n}=79)$ and vascular dementia (VAD [n=87]). Important inclusion criteria were inpatients aged between 60 and 80 years with a MMSE score $<10$, GDS stages 5 to 7. Since no brain imaging was done, the diagnosis $\mathrm{AD}$ or VAD was further based on the Haschinsky Ischemic Score (HIS). A HIS $<5$ was associated with probable AD. Primary endpoints were the 7-point Clinical Global Impression of Change (CGI-C) scale and the BGP-care dependency subscale. The Clinical Global Impression of Severity of illness (CGI-S) scale and the BGP total score together with the D-scale (designed to evaluate behavioral and functional activities in demented patients) were used as secondary efficacy variables. In the AD-group, more patients on memantine improved on the CGI-C compared with placebo ( $73 \%$ vs $42 \% \mathrm{p}<0.001)$. Also on the BGP care dependency subscale, memantine treated $\mathrm{AD}$ patients performed better. In the memantine group, the mean BGP care dependency sub score ( \pm standard deviation) fell with $3.5 \pm 12.5$ points from baseline to 12 weeks compared to $1.6 \pm 9.2$ points in the placebo group. In a responder analysis for the combined $\mathrm{AD}$ and VAD group, using combined response criteria (improvement in CGI-C and $\geq 15 \%$ improvement in BGP), response was observed in $61 \%$ of memantine treated patients compared with $26 \%$ of placebo-treated patients. Among the secondary parameters examined in this AD/VAD group, a statistically significant benefit for memantine compared with placebo was also observed in the BGP total score. Memantine patients also performed better than placebo on all items of the D-scale.

Reisberg et al studied the effects of memantine $(20 \mathrm{mg} / \mathrm{d})$ in 181 patients with moderate to severe AD (MRZ-9605). ${ }^{4}$ In the ITT-LOCF analysis at the end of the 26 weeks follow up period, memantine treated patients had statistically significant better scores on the ADL and cognitive endpoints (ADCS-ADL score, $\mathrm{p}=0.02$; SIB $\mathrm{p}<0.001$ ) compared to placebo. Borderline significance was found for global functioning (CIBIC-plus score; $p=0.06$ ). When analysis was based on observed cases, this primary endpoint also reached statistical significance. A separate analysis was performed comparing the percentage of responders in both treatment groups. Two responder definitions were used. In the first definition, a responder was defined as 'each patient that improved or had no deterioration on the CIBIC-Plus, ADCS-ADL and SIB'. In the second analysis a responder was less strictly defined as 'each patient that improved or had no deterioration on the CIBIC-Plus and who had improved or had no deterioration on either the ADCS-ADL or the SIB'. For the first responder analysis (that was left out of the publication) there was no statistically significant difference between treatment groups $(p=0.17) ; 11 \%$ of memantine and $6 \%$ of placebo group were 
Table I Published double-blinded randomized controlled trials with memantine

\begin{tabular}{|c|c|c|c|c|c|}
\hline Study & MMSE & $\begin{array}{l}\text { Number of patients } \\
\text { (intervention/placebo) }\end{array}$ & $\begin{array}{l}\text { Follow-up } \\
\text { (weeks) }\end{array}$ & $\begin{array}{l}\text { Age } \\
\text { (mean) }\end{array}$ & Outcomes (ITT-LOCF) \\
\hline \multirow[t]{3}{*}{ Winblad (1999) 3} & $<10$ & $82(4 \mid \mathrm{AD}) / 84(38 \mathrm{AD})$ & 12 & 68 male & CGI-C 0.002 \\
\hline & & & & 74 female & BGP-care dependence 0.003 \\
\hline & & & & & BGP-total 0.007 \\
\hline \multirow[t]{7}{*}{ Reisberg (2003)4 MRZ 9605} & $3-14$ & $126 / 126$ & 28 & 75 & ADCS-ADL 0.02 \\
\hline & & & & & CIBIC-plus 0.06 \\
\hline & & & & & $\mathrm{SIB}<0.00 \mathrm{I}$ \\
\hline & & & & & MMSE ns \\
\hline & & & & & FAST 0.02 \\
\hline & & & & & GDS ns \\
\hline & & & & & NPI ns \\
\hline \multirow[t]{7}{*}{ van Dyck $(2007)^{24}$ MEM-MD-0I } & $5-14$ & I78/I72 & 24 & 78 & SIB ns \\
\hline & & & & & ADCS-ADL ns \\
\hline & & & & & CIBIC-plus ns \\
\hline & & & & & NPI ns \\
\hline & & & & & FAST 0.09 \\
\hline & & & & & BGP-total ns \\
\hline & & & & & BGP-care dependence 0.08 \\
\hline \multirow[t]{5}{*}{ Tariot $(2004)^{25}$ MEM-MD-02 } & $5-14$ & $203 / 201$ & 24 & 75 & SIB $<0.01$ \\
\hline & & & & & ADCS-ADL 190.03 \\
\hline & & & & & CIBIC-Plus 0.03 \\
\hline & & & & & NPI 0.002 \\
\hline & & & & & BGP-care dependence $0.00 \mathrm{I}$ \\
\hline \multirow[t]{4}{*}{ Peskind (2006) ${ }^{33}$ MEM-MD-I0 } & $10-22$ & $201 / 202$ & 24 & 78 & ADAS-cog 0.003 \\
\hline & & & & & CIBIC-plus 0.004 \\
\hline & & & & & NPI 0.01 \\
\hline & & & & & ADCS-ADL ns \\
\hline \multirow[t]{4}{*}{ Bakchine $(2008)^{35}$} & $1 \mathrm{I}-23$ & $318 / 152$ & 24 & 74 & ADAS-cog ns \\
\hline & & & & & CIBIC-plus ns \\
\hline & & & & & NPI ns \\
\hline & & & & & ADCS-ADL ns \\
\hline \multirow[t]{4}{*}{ Porsteinsson (2008) ${ }^{36}$ MEM-MD-I2 } & $10-22$ & $178 / 172$ & 24 & 75 & ADAS-cog ns \\
\hline & & & & & CIBIC-plus ns \\
\hline & & & & & NPI ns \\
\hline & & & & & ADCS-ADL ns \\
\hline
\end{tabular}

Notes: Primary outcomes are indicated in bold.

responders. In the second analysis $29 \%$ of the memantine and $10 \%$ of the placebo group responded $(\mathrm{p}<0.001)$. On the secondary endpoints MMSE, FAST and GDS, memantine treated patients did better only on the FAST. This study also assessed neuropsychiatric functioning. Unfortunately, no sign of positive effect of memantine on neuropsychiatric symptoms could be found in both LOCF and OC analysis.

For this study, two post-hoc analyses were published. ${ }^{26,27}$ An analysis of resource utilization and a cost analysis showed that less caregiver time was needed for patients receiving memantine than for those receiving placebo (difference 51.5 hours per month; $95 \% \mathrm{CI}-95.27,-7.17 ; \mathrm{p}=0.02) .{ }^{26}$ Analysis of residential status also favored memantine: time to institutionalization $(\mathrm{p}=0.052)$ and institutionalization at week $28(\mathrm{p}=0.04)$. However, absolute numbers were low. Only one patient in the memantine group and 5 patients in the placebo group were institutionalized. Total costs from a societal perspective were lower in the memantine 
group $(\mathrm{p}=0.01)$. The second post-hoc analysis studied the effect of memantine on activities of daily living. ${ }^{27}$ For this analysis, based on ADCS-ADL scores, two ADL subtypes were created and scored. Based on the combination of these scores, patients were classified as autonomous or dependent. Further analysis showed that a patient treated with memantine was more than 3 times as likely $(\mathrm{OR}=3.03 ; 95 \% \mathrm{CI}=[1.38$, 6.66]) to be autonomous after 6 months.

Finally, the study was followed by a 24 -week open-label extension study. ${ }^{28}$ In this extension study, all patients received memantine in a maintenance dose of $20 \mathrm{mg} / \mathrm{d}$. Blinding for treatment during the preceding double-blind 28-week period was maintained. Of 181 patients who completed the double-blind phase, 80 patients treated with placebo and 95 patients treated with memantine opted to enter the openlabel extension. For patients in the former placebo group, switching to memantine, treatment resulted in a significantly slower rate of decline on the ADCS-ADL, the CIBIC-Plus and the SIB compared with the mean rate of decline during the double-blind placebo period.

In the third study by van Dyck et al (MEM-MD-01), patients with probable $\mathrm{AD}$ were assigned to memantine (20 mg/d) or placebo during a 24-week follow-up period. ${ }^{24}$ Study population and chosen endpoints were largely comparable with the Reisberg study. Surprisingly, and in contrast with the outcomes of the Reisberg study, for none of the primary and secondary endpoints a benefit for memantine was found at 24 weeks. At weeks 12 and 18, a statistically significant advantage on the SIB and CIBIC-Plus was observed for memantine in the LOCF-analysis, but this disappeared at week 24 . Several post-hoc analyses, using different statistical techniques, were performed in order to explain the difference in outcomes with earlier studies. Despite these analyses, no explanation could be found, suggesting that other unexplained factors may be involved. ${ }^{24}$

The results of the fourth DBRCT were published by Tariot et al (MEM-MD-02). ${ }^{25}$ The study design and chosen efficacy parameters used in this study are also largely comparable with the Reisberg and van Dyck studies except for one point. The use of cholinesterase inhibitors was forbidden in the earlier studies, while in this study all patients had to be on ongoing cholinesterase inhibitor therapy with donepezil for more than 6 months before entrance into the trial and at a stable dose $(5-10 \mathrm{mg} / \mathrm{d})$ for at least 3 months. The memantine treated group showed favorable outcomes for all predefined efficacy parameters. On the CIBIC-Plus, 55\% of the memantine group was rated as improved or unchanged vs $45 \%$ of the placebo group at end point. This publication was followed by four publications describing post-hoc analyses on over-all responders and most individual outcomes. ${ }^{29-32}$ The post-hoc responder analysis showed the response rates (\%) for stabilization on individual outcomes ([memantine: placebo]: SIB 62.6: 51.6, ADCS$\mathrm{ADL}_{19}$ 45.9: 35.5, CIBIC-Plus 55.2: 44.1 and NPI 60.8: 48). Although all differences were statically significant and numbers needed to treat (NNT) were around 9, the large placebo effect is remarkable. ${ }^{29}$ The effect of memantine on cognitive performance was further assessed in this analysis by creating 4 response categories relative to basement on the SIB (improvement $>0, \geq 4, \geq 8$ and $\geq 12$ points). NNT for these categories ranged from 9 to 20 . The calculated absolute risk reduction between memantine and placebo was significant for the broadest increment ( $>0$-point improvement) and the $\geq 8$-point improvement increment. Definitions of response that required simultaneous stabilization on multiple outcome measures again favored memantine treatment for 6 out of 10 combinatorial response definitions. The positive effects of memantine on the secondary outcome NPI triggered another post-hoc exploratory analysis by Cummings et al. ${ }^{30}$ Mean baseline NPI scores of 13.8 for the placebo group and 13.7 for the memantine group indicate that most patients in the trial had low to moderate levels of psychopathology at entry. At week 24 , the placebo group continued to deteriorate behaviorally whereas the memantine group returned approximately to baseline $(p=0.002)$. Memantine treated patients scored better on the NPI items: agitation/aggression and appetite/eating changes. No behaviors worsened significantly on memantine compared with placebo. Schmitt et al performed an exploratory analysis on the cognitive response (SIB). ${ }^{31}$ The effects of memantine on individual items of the SIB, subscale performance, and 3 post-hoc-derived aggregate subscales were investigated. The SIB subscale analysis showed statistically significantly greater effects of memantine than placebo on memory, language, and praxis. Finally, Feldman et al focused on ADL effect of memantine using 'observed case' (OC) and 'mixed model repeated measures' (MMRM) approaches. ${ }^{32}$ Three response categories relative to basement on the ADCS$\mathrm{ADL}_{19}$ were created (improvement $>0, \geq 4$ and $\geq 8$ points). Numbers needed to treat for these categories ranged from 10 to 23 . An item analysis revealed statistically significant benefits of memantine on grooming, toileting, conversing, watching television, and being left alone.

\section{Double blinded, randomized controlled trials in mild to moderate $A D$}

In patients with mild to moderate $\mathrm{AD}, 3 \mathrm{DBRCT}$ have been published. 
Peskind at al studied the effect of memantine $20 \mathrm{mg} / \mathrm{d}$ for 24 weeks in 403 US outpatients with AD and MMSE scores of 10 to 22 (MEM-MD-10). ${ }^{33}$ Patients were not allowed to use cholinesterase inhibitors. The study showed a statistically significant difference using ITT-LOCF analysis in favor of the memantine treated group on both primary outcomes cognition (assessed by ADAS-Cog) and global functioning (assessed by CIBIC-Plus). At 24 weeks, memantine treated patients had a statistically significant difference on the ADAS-Cog of -1.9 points compared to placebo. On the CIBIC-Plus, $67.3 \%$ of memantine treated patients were either stabilized or improved compared with $50.8 \%$ of placebo patients. No positive effects of memantine were found on ADL. Memantine treated patients showed better scores on the NPI compared to placebo group ( -3.5 point corrected mean treatment difference). A remarkable outcome in this study was that in the OC analysis, no significant difference between treatment groups could be established for ADAS-Cog and NPI.

Pomara et al performed a post-hoc analysis on these data, examining the effects of memantine on individual items and sub-scales of the ADAS-Cog. ${ }^{34}$ Memantine treatment showed benefits over placebo on subscales language ( 3 out of 4 items) and memory ( 2 out of 5 items) but not on praxis.

Bakchine and Loft performed a 24-week DBRCT with memantine $20 \mathrm{mg} / \mathrm{d}$ in 12 European countries. ${ }^{35}$ Concomitant use of cholinesterase inhibitors was not allowed. Except for a different randomization ratio $(2: 1)$, the study design and chosen outcome variables were largely comparable with the US study by Peskind. For both ADAS-Cog and CIBIC-Plus, a statistically significant benefit from memantine could be established on 12 and 18 weeks, but not on the pre-determined endpoint of 24 weeks. For both ADL and neuropsychiatric problems no benefit of memantine was found on every time point. The authors believe that these unexpected results may be attributed to the unexpected improvement in the placebo group on both ADAS-Cog and CIBIC in the last weeks of the study.

In the study by Porsteinsson et al the efficacy and safety of memantine $20 \mathrm{mg} / \mathrm{d}$ was studied in patients with mild to moderate $\mathrm{AD}$ receiving a stable dose of a cholinesterase inhibitor (donepezil, rivastigmine, galantamine).$^{36}$ Outcome measures were identical to both other studies in mild to moderate AD. At the end of the 24-week evaluation, this study also showed no statistically significant differences between the memantine- and placebo group on primary and secondary outcome measures.

\section{Post-hoc pooled data analyses}

It must be concluded that the statistical benefit of memantine on cognition, global functioning and ADL is not found in all studies in moderate to severe AD. Trials in mild to moderate AD even show worse data. Since small effects in individual studies may be detected in larger cohorts, mainly by smaller confidence intervals, several reports have been published in which the results of the DBRCT are pooled. ${ }^{37-42}$ Although these meta-analyses differ slightly in methodology, basically all these studies show small but statistically relevant differences in favor of memantine on cognition and global functioning in patients with moderate to severe AD. However, meta-analyses may differ in quality and outcomes should be looked at with caution. Most meta-analyses may include both studies in mild to moderate and moderate to severe AD, which clinically does not make sense. Also, combining of data from trials with and without the use of cholinesterase inhibitors is not logical.

As is shown in Table 1, memantine showed a statistically significant effect on the NPI in only 2 studies. Maidment et al pooled NPI data from 5 studies ${ }^{4,24,25,33,34,36}$ Using a random effects model, the total difference in mean NPI value was small but statistically significant $(-1.99 ; 95 \% \mathrm{Cl}-0.08$ to $-3.91 ; \mathrm{p}=0.041)$. The negative results from the study by Backchine were not included in this analysis. Given the fact that the upper-limit of the confidence interval in the pooled analysis almost includes zero, it is reasonable to assume that inclusion of this study would have shifted the confidence intervals in which case statistical significance could have been lost. Wilcock et al performed another analyses on behavioral effects. ${ }^{44}$ They pooled the data from 3 studies $^{4,24,25}$ in moderate to severe AD. The effects of memantine and placebo now were analyzed in the 593 patients who scored at baseline on one the NPI items agitation/ aggression, delusions or hallucinations. At 24 weeks, a significant proportion of memantine treated patients showed improvement on this symptom cluster compared to placebo ( $58 \%$ vs $44.8 \% ; p=0.008)$. On the individual items, only for the item agitation/aggression a statically higher proportion of responders was found in the memantine treated group (61 vs $45 \%$; $\mathrm{p}<0.01$ ). Of those patients who were asymptomatic at baseline, significantly fewer memantine treated patients went on to develop these symptoms ( 24.2 vs $37 \%$; $p=0.007$ ). The possible effects of memantine on neuropsychiatric functioning are indirectly supported by data from the French national Health Care Database. In a sample of 4600 memantine treated patients psychotropic drug use before and after onset of memantine was analyzed. Before memantine onset, an increasing trend for psychotropic drug use could be seen. After memantine initiation, psychotropic drug use stabilized (but did not decrease). ${ }^{45}$ 


\section{Economic effects}

Many studies have been presented focusing on costeffectiveness of memantine. ${ }^{46-53}$

These studies are very difficult to interpret or compare to other cost-effectiveness studies. Although cost-effectiveness for memantine is claimed in these studies, data are difficult to interpret since used models are not always presented in a clear way and assumptions made to build the models can be discussed ${ }^{54} \mathrm{~A}$ large problem with these analyses is the lack of consensus how to measure costs and how to value benefits. For instance, in the cost-effectiveness study by Wimo et al caregiver time was valued at US\$9.18 to $\$ 23.65 /$ hour, depending on factors like age and gender of the caregiver, whereas in a study of donepezil in moderate to severe AD this was valued at only US\$4.6/hour. ${ }^{26,55}$ A higher valuation of items that are positively influenced by memantine at equal costs automatically increases the benefits of the drug. Also, the found cost-effectiveness calculations are mainly based on the results of positive trials. It must be noted that the last three published trials that failed to show these positive effects are often not used for modeling. The NICE Committee discussed cost-effectiveness based on information provided by the registration holders. This also included non-public and non-published information. They concluded that, on the basis of current evidence on clinical effectiveness, memantine could not reasonably be considered a cost-effective therapy for moderately severe to severe Alzheimer's disease. ${ }^{5}$ So, with contradicting views on how to measure effectiveness and costs, a definite valuation of the cost-effectiveness of memantine will be difficult. Determining effectiveness in terms of utilities like Quality Adjusted Life Years (QALYs) is even more difficult since there is a lack of well-validated or uniformly accepted measures of quality of life in dementia. The few data on current QALY estimates for dementia have been subject to widely different interpretations. ${ }^{56}$

\section{Safety and tolerability}

Recently, Farlow et al published pooled data concerning tolerability and safety from data from trial data. ${ }^{57}$ In this analysis, not only published data but also data on file from manufacturers (Forest Laboratories, Inc., Merz Pharmaceuticals GmbH and $\mathrm{H}$. Lundbeck A/S) were used. It was concluded that the tolerability and safety of memantine in patients with $\mathrm{AD}$ is almost indistinguishable from that of placebo. However, these data provided and published by the manufacturers themselves may be biased. Less changes of bias can be expected in safety data presented by Registration authorities (eg, EMEA and FDA). For the purpose of monitoring the safety aspects of registered drugs, these authorities can use several sources of information. Firstly, data from all trials are used. Furthermore, following registration, registration holders must provide periodic data concerning serious side effects that occurred during the post registration phase, the so-called Periodic Safety Update Reports (PSURs). These PSURs are not public. Because of this non-public nature of part of the safety data, product characteristics provided by registration authorities are the most complete source of information. A third source for safety data can be found in the spontaneous reports from patients and health care providers. These data that are collected by national organizations are grouped in the WHO Collaborating Centre for International Drug Monitoring. The Summary of Product Characteristics (SPC) as provided by the EMEA summarizes adverse drug reactions (ADRs) found in clinical trials in mild to severe dementia. In 1784 patients treated with Memantine and 1595 patients treated with placebo, the overall incidence rate of adverse reactions with memantine did not differ from those with placebo; the adverse events were usually mild to moderate in severity. The most frequently occurring adverse events with a higher incidence in the memantine group than in the placebo group were dizziness ( $6.3 \%$ vs $5.6 \%$, respectively), headache $(5.2 \%$ vs $3.9 \%$ ), constipation ( $4.6 \%$ vs $2.6 \%$ ), somnolence ( $3.4 \%$ vs $2.2 \%$ ) and hypertension ( $4.1 \%$ vs $2.8 \%) .{ }^{58}$ Reported adverse drug reactions from this SPC are listed in Table 2.

With the exception of the Winblad study, all presented studies studied the safety and efficacy of memantine $20 \mathrm{mg} / \mathrm{d}$, given as $10 \mathrm{mg}$ bid. The safety and tolerability of a different dosing schedule has been studied in a 28-week open label extension study (MEM-MB-11AB) to the study by Peskind. In this study, the safety and tolerability of memantine $20 \mathrm{mg}$ once-daily was compared with standard dose of $10 \mathrm{mg}$ twice daily. ${ }^{59}$ Individual adverse events in the once-daily dosage regimen were similar with those in the twice-daily regimen (perhaps with slightly more agitation and somnolence in the once-daily regimen), indicating that once-daily dosing is safe and well tolerated.

Jones et al studied 3 dosing schedules (20 mg once daily with a 3-step up-titration, $20 \mathrm{mg}$ once daily with a 1-step uptitration and $10 \mathrm{mg}$ twice daily with a 3-step up-titration) in a 12-week DBRCT in 78 patients. ${ }^{60}$ Given the small numbers in each group, solid conclusions can not be drawn. The authors conclude that once-daily dosing and twice-daily dosing of memantine are similar in terms of safety and tolerability.

\section{Conclusions}

Randomized controlled trials of memantine in AD patients show very different outcomes. With some caution, it may 
Table 2 Adverse drug reactions of memantine

\begin{tabular}{lll}
\hline Nervous system disorders & Common & Dizziness \\
& Uncommon & Gait abnormal \\
Gastrointestinal disorders & Very rare & Seizures \\
& Common & Vomitipation \\
& Uncommon & Pancreatitis \\
Infections & Not known & Fungal infections \\
Vascular disorders & Uncommon & Hypertension \\
& Common & Venous thrombosis/thromboembolism \\
General disorders and administration site & Uncommon & Headache \\
conditions & Common & Fatigue \\
Psychiatric disorders & Uncommon & Somnolence \\
& Common & Confusion \\
& Uncommon & Hallucinations \\
\end{tabular}

Notes: Very common $(\geq \mathrm{I} / \mathrm{I} 0)$, common $(\geq \mathrm{I} / \mathrm{I} 00$ to $<\mathrm{I} / \mathrm{I} 0)$, uncommon $(\geq \mathrm{I} / \mathrm{I}, 000$ to $<\mathrm{I} / \mathrm{I} 00)$, rare $(\geq \mathrm{I} / \mathrm{I} 0,000$ to $<\mathrm{I} / \mathrm{I}, 000)$, very rare $(<\mathrm{I} / \mathrm{I} 0,000)$, not known (cannot be estimated from the available data).

alsolated cases reported in post-marketing experience.

bHallucinations have mainly been observed in patients with severe Alzheimer's disease.

be concluded that possible effects are larger in patients with moderate to severe $\mathrm{AD}$ than in patients with mild to moderate $\mathrm{AD}$. Two out of 3 trials in the MMSE range 10 to 22 were negative at the end of the predefined period of 26 weeks on all outcomes. As cholinesterase inhibitor therapy is almost standard in mild to moderate $\mathrm{AD}$, studies comparing memantine treatment with placebo must be considered clinically less relevant. The only study describing the effects of memantine in patients with mild to moderate $\mathrm{AD}$ on stable cholinesterase inhibitor therapy fails to show a positive effect on every outcome. However, in moderate to severe $\mathrm{AD}$, addition of memantine to a donepezil may be useful. This potential positive effect of combination therapy is supported by a retrospective analysis of $382 \mathrm{AD}$ patients that were treated in a Memory Disorders Unit with a mean follow-up of 30 months. Combination therapy was more effective in slowing cognitive and functional decline than therapy with ChEIs alone. These effects were sustained for the whole follow-up period. ${ }^{61}$

For patients with a MMSE above 14, data do not support the prescription of memantine. The meta-analysis by Doody et al show that, half of the patients in the moderate to severe trials tended toward the moderate and most patients in mild to moderate trials tended toward the more mild range. Since effect sizes tended to be larger in the moderate to severe than in the mild to moderate trials, there is a relative lack of evidence for memantine's efficacy at the more mild and severe ends of the MMSE range. ${ }^{41}$ So available evidence points towards statistical significant effects of memantine in patients with an MMSE $<14$. Since both studied patient groups show an overlap in the MMSE range of 10 to 14 it is difficult to draw conclusions on the effect of memantine in this range. It would have been clearer if outcomes had been pooled for smaller, non-overlapping MMSE categories. But, even in the group with low MMSE scores, the found effects of memantine on cognition, global functioning, ADL and neuropsychiatric symptoms are small. Do these found efficacy data, also mean clinical relevant effectiveness? A clinically relevant treatment can be defined as one in which the change is both relevant and important to the patient or caregiver. It is difficult to create cut-off scores for relevance on individual assessment scales. As will be clear from presented studies, many study groups create new definitions for clinical relevance in their post-hoc analysis. But, accepting clinical effectiveness based on post-hoc analyses is incorrect. Post-hoc analyses must be the basis for further research, not the basis for solid conclusions. The effects of shifting of criteria for response are shown in the Reisberg study. In the responder analyses, strict response criteria (stabilization on all three primary outcomes) presented in the European Public Assessment Report (EPAR), resulted in non-significant results. Only $11 \%$ of the memantine group were responders. ${ }^{12}$ With a less strict response definition (stabilization on 2 out of 3 primary outcomes), presented in 
the published manuscript, $29 \%$ of the memantine and $10 \%$ of the placebo group responded. ${ }^{4,12}$

Another problem is that goals for treatment will vary with disease stage. In early stages, the aim is to improve cognition and slow progression of disease. In the mid-stages of the disease, the emphasis is on preserving function (that is, ADLs) and delaying institutionalization. In the late stages in which many patients will be institutionalized, the emphasis moves toward management of difficult behaviors.

So, it must be concluded that memantine is a relatively safe drug with few side effects and neglectable risk of drug-drug interactions but only small clinical relevant effects on cognition, global functioning and ADL, mainly in patients with moderate AD. Furthermore, it may have some effects on neuropsychiatric functioning (especially on agitation/ aggression, delusions or hallucinations), but more studies on this topic are needed for solid conclusions.

\section{Disclosures}

The author has no conflicts of interest to declare.

\section{References}

1. Gerzon K, et al. The adamantyl group in medicinal agents. I. Hypoglycemic N-arylsulfonyl-N'-adamantylureas. J Med Chem. 1963;6:760-763.

2. Fleischhacker WW, Buchgeher A, Schubert H. Memantine in the treatment of senile dementia of the Alzheimer type. Prog Neuropsychopharmacol Biol Psychiatry. 1986;10(1):87-93.

3. Winblad B, Poritis N. Memantine in severe dementia: results of the 9MBest Study (Benefit and efficacy in severely demented patients during treatment with memantine). Int J Geriatr Psychiatry. 1999;14(2):135-146.

4. Reisberg B, Doody R, Stöffler A, Schmitt F, Ferris S, Möbius HJ; Memantine Study Group. Memantine in moderate-to-severe Alzheimer's disease. N Engl J Med. 2003;348(14):1333-1341.

5. NICE technology appraisal guidance 111. Donepezil, galantamine, rivastigmine (review) and memantine for the treatment of Alzheimer's disease (amended). National Institute for Health and Clinical Excellence. London; Sept 2007.

6. Paoletti P, Neyton J. NMDA receptor subunits: function and pharmacology. Curr Opin Pharmacol. 2007;7(1):39-47.

7. Parsons CG, Stöffler A, Danysz W. Memantine: a NMDA receptor antagonist that improves memory by restoration of homeostasis in the glutamatergic system - too little activation is bad, too much is even worse. Neuropharmacology. 2007;53(6):699-723.

8. Kalia LV, Kalia SK, Salter MW. NMDA receptors in clinical neurology: excitatory times ahead. Lancet Neurol. 2008;7(8):742-755.

9. Chohan MO, Iqbal K. From tau to toxicity: emerging roles of NMDA receptor in Alzheimer's disease. J Alzheimers Dis. 2006;10(1):81-87.

10. Degerman Gunnarsson M, Kilander L, Basun H, Lannfelt L. Reduction of phosphorylated tau during memantine treatment of Alzheimer's disease. Dement Geriatr Cogn Disord. 2007;24(4):247-52.

11. European Medicines Agency: European Public Assessment Report (EPAR) http://www.emea.europa.eu/humandocs/PDFs/EPAR/ebixa/ 160402en6.pdf

12. Shua-Haim J, Smith J, Picard F, et al. Steady-state pharmacokinetics of rivastigmine in patients with mild to moderate Alzheimer's disease not affected by co-administration of memantine: an open-label, crossover, single-centre study. Clin Drug Investig. 2008;28(6):361-374.
13. Yao C, Raoufinia A, Gold M, et al. Steady-state pharmacokinetics of galantamine are not affected by addition of memantine in healthy subjects. J Clin Pharmacol. 2005;45(5):519-528.

14. Periclou AP, Ventura D, Sherman T, Rao N, Abramowitz WT. Lack of pharmacokinetic or pharmacodynamic interaction between memantine and donepezil. Ann Pharmacother. 2004;38(9):1389-94.

15. Periclou A, Ventura D, Rao N, Abramowitz W. Pharmacokinetic study of memantine in healthy and renally impaired subjects. Clin Pharmacol Ther. 2006;79(1):134-143.

16. Freudenthaler S, Meineke I, Schreeb KH, Boakye E, Remy UG, Gleiter $\mathrm{CH}$. Influence of urine $\mathrm{pH}$ and urinary flow on the renal excretion of memantine. Br J Clin Pharmacol. 1998;46:541-546.

17. Winblad B, Wimo A, Almkvist O. Outcome measures in Alzheimer's disease: do they go far enough? Dement Geriatr Cogn Disord. 2000;11 suppl 1:3-10.

18. Reisberg B. Global measures: utility in defining and measuring treatment response in dementia. Int Psychogeriatr. 2007;19(3):421-456.

19. Schmitt FA, Ashford W, Ernesto C, et al. The severe impairment battery: concurrent validity and the assessment of longitudinal change in Alzheimer's disease. Alzheimer Dis Assoc Disord. 1997;11 suppl 2: S51-S56.

20. Rosen WG, Mohs RC, Davis KL. A new rating scale for Alzheimer's disease. Am J Psychiatry. 1984;141(11):1356-1364.

21. Galasko D, Bennett D, Sano M, et al. An inventory to assess activities of daily living for clinical trials in Alzheimer's disease. Alzheimer Dis Assoc Disord. 1997;11 suppl 2:S33-S39.

22. van der Kam P, Mol F, Wimmers MFHC. Beoordelingsschaal voor oudere patienten (BOP). Deventer, The Netherlands: Van Loghum Slaterus; 1971.

23. Cummings JL, Mega M, Gray K, Rosenberg-Thompson S, Carusi DA, Gornbein J. The Neuropsychiatric Inventory: comprehensive assessment of psychopathology in dementia. Neurology. 1994;44(12):2308-2314.

24. van Dyck CH, Tariot PN, Meyers B, Malca Resnick E; the Memantine MEM-MD-01 Study Group. A 24-week randomized, controlled trial of memantine in patients with moderate-to-severe Alzheimer disease. Alzheimer Dis Assoc Disord. 2007;21(2):136-143.

25. Tariot PN, Farlow MR, Grossberg GT, Graham SM, McDonald S, Gergel I; Memantine Study Group. Memantine treatment in patients with moderate to severe Alzheimer disease already receiving donepezil: a randomized controlled trial. JAMA. 2004;291(3):317-324.

26. Wimo A, Winblad B, Stöffler A, Wirth Y, Möbius HJ. Resource utilisation and cost analysis of memantine in patients with moderate to severe Alzheimer's disease. Pharmacoeconomics. 2003;21(5):327-340.

27. Rive B, Vercelletto M, Damier FD, Cochran J, François C. Memantine enhances autonomy in moderate to severe Alzheimer's disease. Int $J$ Geriatr Psychiatry. 2004;19(5):458-464.

28. Reisberg B, Doody R, Stöffler A, Schmitt F, Ferris S, Möbius HJ. A 24-week open-label extension study of memantine in moderate to severe Alzheimer disease. Arch Neurol. 2006;63(1):49-54.

29. van Dyck CH, Schmitt FA, Olin JT. Memantine MEM-MD-02 Study Group. A responder analysis of memantine treatment in patients with Alzheimer disease maintained on donepezil. Am J Geriatr Psychiatry. 2006;14(5):428-437.

30. Cummings JL, Schneider E, Tariot PN, Graham SM; Memantine MEM-MD-02 Study Group. Behavioral effects of memantine in Alzheimer disease patients receiving donepezil treatment. Neurology. 2006;67(1):57-63.

31. Schmitt FA, van Dyck CH, Wichems CH, Olin JT; the Memantine MEM-MD-02 Study Group. Cognitive response to memantine in moderate to severe Alzheimer disease patients already receiving donepezil: an exploratory reanalysis. Alzheimer Dis Assoc Disord. 2006;20(4):255-262.

32. Feldman HH, Schmitt FA, Olin JT; Memantine MEM-MD-02 Study Group. Activities of daily living in moderate-to-severe Alzheimer disease: an analysis of the treatment effects of memantine in patients receiving stable donepezil treatment. Alzheimer Dis Assoc Disord. 2006;20(4):263-268. 
33. Peskind ER, Potkin SG, Pomara N, et al. Memantine treatment in mild to moderate Alzheimer disease: a 24-week randomized, controlled trial. Am J Geriatr Psychiatry. 2006;14(8):704-715.

34. Pomara N, Ott BR, Peskind E, Resnick EM. Memantine treatment of cognitive symptoms in mild to moderate Alzheimer disease: secondary analyses from a placebo-controlled randomized trial. Alzheimer Dis Assoc Disord. 2007;21(1):60-64.

35. Bakchine $\mathrm{S}$, Loft $\mathrm{H}$. Memantine treatment in patients with mild to moderate Alzheimer's disease: results of a randomised, double-blind, placebocontrolled 6-month study. J Alzheimers Dis. 2008;13(1):97-107.

36. Porsteinsson AP, Grossberg GT, Mintzer J, Olin JT; Memantine MEM-MD-12 Study Group. Memantine treatment in patients with mild to moderate Alzheimer's disease already receiving a cholinesterase inhibitor: a randomized, double-blind, placebo-controlled trial. Curr Alzheimer Res. 2008;5(1):83-89.

37. McShane R, Areosa Sastre A, Minakaran N. Memantine for dementia. Cochrane Database Syst Rev. 2006;(2):CD003154.

38. Emre M, Mecocci P, Stender K. Pooled analyses on cognitive effects of memantine in patients with moderate to severe Alzheimer's disease. J Alzheimers Dis. 2008;14(2):193-199.

39. Winblad B, Jones RW, Wirth Y, Stöffler A, Möbius HJ. Memantine in moderate to severe Alzheimer's disease: a meta-analysis of randomised clinical trials. Dement Geriatr Cogn Disord. 2007;24(1):20-27.

40. Wilkinson D, Andersen HF. Analysis of the effect of memantine in reducing the worsening of clinical symptoms in patients with moderate to severe Alzheimer's disease. Dement Geriatr Cogn Disord. 2007;24(2):138-145.

41. Doody RS, Tariot PN, Pfeiffer E, Olin JT, Graham SM. Meta-analysis of six-month memantine trials in Alzheimer's disease. Alzheimers Dement. 2007;3(1):7-17.

42. Raina P, Santaguida P, Ismaila A, et al. Effectiveness of cholinesterase inhibitors and memantine for treating dementia: evidence review for a clinical practice guideline. Ann Intern Med. 2008;148(5):379-397.

43. Maidment ID, Fox CG, Boustani M, Rodriguez J, Brown RC, Katona CL. Efficacy of memantine on behavioral and psychological symptoms related to dementia: a systematic meta-analysis. Ann Pharmacother. 2008;42(1):32-8.

44. Wilcock GK, Ballard CG, Cooper JA, Loft H. Memantine for agitation/aggression and psychosis in moderately severe to severe Alzheimer's disease: a pooled analysis of 3 studies. J Clin Psychiatry. 2008;69(3):341-38.

45. Vidal JS, Lacombe JM, Dartigues JF, et al. Evaluation of the impact of memantine treatment initiation on psychotropics use: a study from the French national health care database. Neuroepidemiology. 2008;31(3):193-200.

46. Weycker D, Taneja C, Edelsberg J, et al. Cost-effectiveness of memantine in moderate-to-severe Alzheimer's disease patients receiving donepezil. Curr Med Res Opin. 2007;23(5):1187-1197.
47. Gagnon M, Rive B, Hux M, Guilhaume C. Cost-effectiveness of memantine compared with standard care in moderate-to-severe Alzheimer disease in Canada. Can J Psychiatry. 2007;52(8):519-526.

48. François C, Sintonen H, Sulkava R, Rive B. Cost effectiveness of memantine in moderately severe to severe Alzheimer's disease: a markov model in Finland. Clin Drug Investig. 2004;24(7):373-384.

49. Antonanzas F, Rive B, Badenas JM, Gomez-Lus S, Guilhaume C. Cost-effectiveness of memantine in community-based Alzheimer's disease patients: An adaptation in Spain. Eur $J$ Health Econ. 2006;7(2):137-144.

50. Kirby J, Green C, Loveman E, et al. A systematic review of the clinical and cost-effectiveness of memantine in patients with moderately severe to severe Alzheimer's disease. Drugs Aging. 2006;23(3):227-240.

51. Loveman E, Green C, Kirby J, et al. The clinical and cost-effectiveness of donepezil, rivastigmine, galantamine and memantine for Alzheimer's disease. Health Technol Assess. 2006;10(1):iii-iv, ix-xi, 1-160.

52. Jönsson L. Cost-effectiveness of memantine for moderate to severe Alzheimer's disease in Sweden. Am J Geriatr Pharmacother. 2005; 3(2):77-86.

53. Jones RW, McCrone P, Guilhaume C. Cost effectiveness of memantine in Alzheimer's disease: an analysis based on a probabilistic Markov model from a UK perspective. Drugs Aging. 2004;21(9):607-620.

54. Geldmacher DS Cost-effectiveness of drug therapies for Alzheimer's disease: A brief review. Neuropsychiatr Dis Treat. 2008;4(3): 549-555.

55. Feldman H, Gauthier S, Hecker J, et al. Economic evaluation of donepezil in moderate to severe Alzheimer disease. Neurology. 2004;63:644-650.

56. Neumann, PJ. Health utilities in Alzheimer's disease and implications for cost-effectiveness analysis. Pharmacoeconomics. 2005;23:437-541.

57. Farlow MR, Graham SM, Alva G. Memantine for the treatment of Alzheimer's disease: tolerability and safety data from clinical trials. Drug Saf. 2008;31(7):577-85.

58. European Medicines Agency: Summary of Product Characteristics http://www.emea.europa.eu/humandocs/PDFs/EPAR/ebixa/H-463PI-en.pdf

59. Ott BR, Blake LM, Kagan E, Resnick M; the Memantine MEMMD-11AB Study Group. Open label, multicenter, 28-week extension study of the safety and tolerability of memantine in patients with mild to moderate Alzheimer's disease. J Neurol. 2007;254(3): 351-358.

60. Jones RW, Bayer A, Inglis F, Barker A, Phul R. Safety and tolerability of once-daily versus twice-daily memantine: a randomised, double-blind study in moderate to severe Alzheimer's disease. Int $J$ Geriatr Psychiatry. 2007;22(3):258-262.

61. Atri A, Shaughnessy LW, Locascio JJ, Growdon JH. Long-term course and effectiveness of combination therapy in Alzheimer disease. Alzheimer Dis Assoc Disord. 2008;22(3):209-221. 
